\title{
Covid-19: Patients who are improving could have treatment withdrawn if others could benefit more
}

\author{
Elisabeth Mahase
}

The BMJ

Doctors could be forced to withdraw lifesaving treatment from stable or improving patients to prioritise those deemed likely to have a better prognosis if the demand on the heath service during the covid-19 pandemic outstrips the capacity.

This is according to new ethics guidance from the BMA. ${ }^{1}$ It states that although the decision to deny treatment to a patient who would have received it outside a pandemic will be difficult for doctors, it may become necessary, and it is "both lawful and ethical," as long as they follow the appropriate prioritisation policies.

"As we have seen in China, Italy and Spain, deaths frequently follow hospitalisation and critical care interventions ... It is possible therefore that restrictions in the availability of mechanical ventilation may for a period become severe," the document said.

It warned that "the initial wave of illness can be extremely rapid, over a few days to a few weeks," and that in these circumstances, if demand outstripped capacity, "more strictly utilitarian considerations will have to be applied, and decisions about how to meet individual need will give way to decisions about how to maximise overall benefit."

It advised doctors that they may need to make admission to intensive care or access to advanced life support dependent on whether the patient responded to treatment in a certain timeframe. This would mean that if there were "overwhelming demand" a patient may have their admission or treatment withdrawn if their prognosis sufficiently worsened. Their place would then be offered to another patient "reasonably believed to have the capacity to benefit quickly."

\section{Discrimination}

When patients are refused access to lifesaving treatments, it is likely that questions about possible discrimination may be raised. As the assessment will be based on the capacity to benefit quickly, some of the most unwell patients may be denied access to treatment such as intensive care or artificial ventilation. It was inevitable that this would be "indirectly discriminatory against both the elderly and those with long term health conditions," the BMA said. Despite this, it views this way of assessing patients as "lawful in the circumstances of a serious pandemic."

However, doctors have been advised that a "simple cut-off policy with regard to age or disability would be unlawful as it would constitute direct discrimination."

The guidance states, "A healthy 75 year old cannot lawfully be denied access to treatment on the basis of age. However, older patients with severe respiratory failure secondary to covid-19 may have a very high chance of dying despite intensive care, and consequently have a lower priority for admission to intensive care."

\section{Liability}

During this period, doctors have also been told that it is likely that they will be exposed to "considerable amounts of stress, may be working well beyond their normal hours," and may also need to "provide treatment at the limits of or even beyond their competence in order to prevent serious harm."

Additionally, in light of returning retired doctors and medical students contributing to the covid-19 response, there will inevitably be questions about professional and legal liability and indemnity. The BMA referred to General Medical Council guidance that states, "Whenever a concern is raised with us, we always consider it on the specific facts of the case, taking into account the factors relevant to the environment in which the doctor is working ... The scale of the challenges to delivering safe care would be relevant to a question about the clinical care provided by a doctor. In addition, we'd consider the resources available to the doctor, the problems of working in unfamiliar areas of practice, and the stress and tiredness that may affect judgment or behaviour."

1 BMA. COVID-19: ethical issues. Apr 2020. https://www.bma.org.uk/advice-and-support covid-19/ethics/covid-19-ethical-issues.

Published by the BMJ Publishing Group Limited. For permission to use (where not already granted under a licence) please go to http://group.bmj.com/group/rights-licensing/ permissions 